\title{
Evaluación turística territorial. Caso de estudio: Cojimíes, Ecuador
}

Territorial tourism evaluation. Case study: Cojimíes, Ecuador

Avaliação do turismo territorial. Estudo de caso: Cojimíes, Equador

Yamil Doumet Chilán/ Escuela Superior Politécnica Agropecuaria de Manabí/ndoumet@espam.edu.ec

Recibido: 20/2/2021 Aceptado: 12/4/2021 Publicado: 25/6/2021

\section{RESUMEN}

La investigación tuvo como objetivo evaluar las potencialidades turísticas de la parroquia Cojimíes del cantón Pedernales, Ecuador. Para ello se valoraron las características naturales, culturales y recreativas del territorio. La investigación fue de carácter descriptivo con enfoque mixto. El diagnóstico del sistema turístico se realizó mediante la revisión bibliográfica, visitas al campo y técnicas de observación directa. El análisis de la gestión turística se realizó a través de la matriz de involucrados, aplicada en la Dirección de Turismo de Pedernales, la Junta Parroquial de Cojimíes y los prestadores de servicios turísticos. De igual manera se realizaron entrevistas a los actores locales para conocer la percepción del turismo en el destino. El estudio de la competencia se fundamentó en la elección de dos sitios con características similares: Pedernales y Mompiche. Para ello, se usó la matriz de perfil competitivo y de manera individual, se observaron los principales aspectos del sector turístico. A través de la evaluación, se evidenciaron las potencialidades turísticas y se propusieron estrategias para el desarrollo del turismo en Cojimíes, integrando a los actores locales, las tendencias actuales y la diversidad natural y cultural.

Palabras clave: actores locales, desarrollo turístico, destinos turísticos, gestión turística, marketing territorial, potencialidades turísticas 


\begin{abstract}
The objective of the research was to evaluate the tourism potential of the municipality of la parroquia Cojimes in the region of Pedernales, Ecuador. The most valuable characteristics of the region are the natural, cultural, and recreational resources. The research was descriptive in nature with a mixed focus. The outcome of the ecological environment was defined through a bibliographical publication, field visits to the area, and technical observation techniques. The analysis of tourism study was carried out through the stakeholder matrix, applied in the Pedernales Tourism Directorate, the Cojimíes Parish Board and the tourism service providers. In the same way, interviews were carried out with local actors to know the perception of tourism in the destination.The study of the competition was based on the choice of two sites with similar characteristics: Pedernales and Mompiche. For this, the competitive profile matrix was used and individually, the main aspects of the tourism sector were observed. Through the evaluation, the tourist potentialities were evidenced and strategies were proposed for the development of tourism in Cojimíes, integrating local actors, current trends and natural and cultural diversity.
\end{abstract}

Keywords: local actors, territorial marketing, tourism destinations, tourism development, tourism management, tourism potential

\title{
RESUMO
}

O presente estudo, teve como objetivo, avaliar as potencialidades do turismo na paróquia rural Cojimíes, no interior de Pedernales, na região de Manabí, no Equador. Valorizando tradições culturais e características naturais e de lazer do território. A busca de dados foi de maneira descritiva com abordagens mistas. Quanto ao diagnóstico do aspecto turístico, ocorreu mediante uma revisão bibliográfica, visitas no campo e técnicas de observação direta. Para as análises de gerenciamento, a matriz de dados consistiu da participação de voluntário sobre uma perspectiva territorial turística do cantão de Pedernales, da paróquia e dos profissionais que trabalham na área do turismo. Da mesma forma, foram realizadas entrevistas com atores locais para conhecer a percepção do turismo no destino. Além disso, competência deste estudo, se fundamentou na seleção dos locais que mais se aproximassem com características territoriais da cidade de Pedernales e Mompiche. Com base num perfil competitivo sendo observados individualmente, os principais aspectos do setor turístico. No entanto, através desta avaliação, se identificou as potencialidades turísticas e foi desenvolvida uma proposta estratégica para o desenvolvimento do turismo em Cojimíes, integrando moradores locais, novas tendências e diversidade natural e cultural.

Palavras chave: atores locais, desenvolvimento do turismo, destinos turísticos, gerenciamento do turismo, marketing territorial, potencial turístico 


\section{INTRODUCCIÓN}

Los procesos de planificación e investigación son lo que hacen posible que se desarrollen regiones donde el turismo pueda ser una herramienta para la gestión local. La planificación estratégica como fundamento facilita la evolución turística, diversifica la economía local y alcanzar la sostenibilidad. Para He et al. (2018) el turismo juega un rol importante en la economía mundial, diversificando el crecimiento económico a nivel local y regional con enfoque mundial. En los países en vías de desarrollo se observan varias limitantes que no permiten que un destino evolucione. Entre las razones mencionadas se encuentran: la falta de promoción y el desconocimiento de las verdaderas potencialidades turísticas de un territorio.

Zengxian y Jigang (2018) expresan que, tanto en el sur de Europa como en América Latina, se encuentran muchas instituciones públicas o en cuyas estructuras la presencia del sector privado es testimonial o simbólica, lo que favorece el retroceso a la hora de plantear estrategias como parte del proceso de planificación. De acuerdo con la Organización de las Naciones Unidas (s. f.), el desarrollo sostenible debe direccionarse hacia la gestión ambiental desde un enfoque integral. Las estrategias dirigidas a disociar el crecimiento y diversificación económica de la degradación ambiental y el uso excesivo de los recursos deben ser fortalecidas y enfocarse en la participación integral de todos los actores y gestores locales. A su vez debe velar de que exista una en la vinculación de todos los componentes del sistema turístico en los procesos de evaluación y gestión territorial. Para Cardoso et al. (2014) el desarrollo turístico debe estar encaminado a uso de forma eficiente los recursos naturales, manteniendo los procesos ecológicos esenciales y la diversidad biológica. De igual modo se hace necesario respetar la autenticidad sociocultural de las comunidades, conservar sus activos culturales y valores tradicionales, así como contribuir a su diversificación económica. De forma planificada, este sería el medio para que los habitantes y sus actores puedan lograr beneficios económicos y mejorar su calidad de vida.

Por otra parte, el turismo como tal, es un sistema conformado por una cadena de valores productivos que pueden ser aprovechados de manera sostenible acorde a las necesidades de los visitantes y a la comunidad local. De allí la importancia de analizar aspectos como fluctuación de la oferta y la demanda, la estructura organizativa y de los espacios socioeconómicos. Para Gómez y Tacuba (2017) el desarrollo con enfoque territorial implica la transformación dinámica y sostenida del medio rural mediante la generación y el aumento de las capacidades productivas de los diversos agentes económicos presentes. El crecimiento debe ser sostenido y direccionado a la revalorización de las manifestaciones culturales y a la conservación ambiental. Con las bases adecuadas y asumiendo la planificación como eje integral este sector se puede transformar en una vía para alcanzar la diversificación económica de un determinado lugar. 
La planificación turística enfocada al desarrollo integral busca tener espacios en un mercado competitivo y exigente. Para Martín y Martín (2017) la creciente competencia a nivel internacional y la calidad de los servicios que se ofrecen son indicadores esenciales en la elección de los destinos. De ahí la importancia de considerar las tendencias actuales y anticipar las necesidades del futuro cliente. Para Roldán et al. (2017) la preparación y capacitación constante permiten que los actores locales y los agentes turísticos tengan las capacidades apropiadas para brindar una oferta de calidad. Por su parte, Cruz y González (2020) interpretan al destino turístico como el resultado de varios procesos que van desde los servicios de calidad hasta una infraestructura innovadora. Para los autores los sitios proyectados para el turismo tienen que estar condicionados y preparados para ofrecer una atención de acuerdo con los estándares internacionales. En tal sentido, Lee et al. (2018) sostienen que en la planificación de un destino hay que considerar el servicio tangible e intangible. Esto implica que las acciones que se desarrollen tienen que ser holísticas y estar direccionadas a invertir en la preparación del personal y el mantenimiento de la planta turística.

Po su parte Buciega y Esparcia (2018) plantean que para el establecimiento de un proceso de desarrollo de productos turísticos rurales sustentables es necesario un diseño adecuado, que identifique las diferencias y características de cada comunidad rural. De igual modo es importante considerar las dimensiones económicas, sociales y ecológicas, a fin de establecer un equilibrio entre estas fuerzas y las propuestas turísticas desarrolladas, generando un impacto positivo en la calidad de vida de las personas. El diagnóstico y la evaluación sería el punto de partida para alcanzar dichos objetivos.

En el caso de Ecuador, el Ministerio de Turismo (2014) manifiesta que la mayor potencialidad con la que cuenta el país es su biodiversidad; por ello, es fundamental conocerla y gestionarla de manera adecuada, mediante su conservación y uso sustentable. Para esto, es prioritario establecer modelos que se fundamenten en la planificación estratégica sostenible. Según Carreño et al. (2017), el turismo ecuatoriano se ha transformado en una de las actividades económicas importantes, debido a la entrada de divisas y a la diversificación del ingreso que genera en los destinos receptivos. Reyes et al. (2014) expresan que el sector constituye uno de los rubros económicos prioritarios, presentándose como estratégico para el desarrollo del país, siendo una actividad que genera empleo y redistribuye la riqueza. De acuerdo a lo expuesto por los autores, el turismo tiene que ser integrador y vincularse con múltiples actividades para la superación de la pobreza y el desarrollo sostenible. De igual forma, Mera y Solórzano (2017) evidencian que la diversidad y potencialidad de los territorios rurales en la provincia Manabí son altas, pero, a su vez, se muestran problemas y debilidades que no permiten el desarrollo integral del turismo.

Según Shen et al. (2017) la experiencia del viaje mejorará con la utilización de 
herramientas como la inteligencia artificial, el internet más eficiente y las redes sociales democráticas e inclusivas. Sin embargo, estos avances constituyen aún un verdadero desafío, ya que en algunas regiones no han terminado de despegar por el desconocimiento y la limitada inversión en la innovación tecnológica, especialmente los países sudamericanos. Con otro enfoque, Ayoví (2018) sostiene que el primer paso para obtener el desarrollo es el diagnóstico de la situación de partida y un análisis exhaustivo de la oferta y la demanda turísticas; además de considerar la matriz de fortalezas, oportunidades, debilidades y amenazas (FODA) para conocer la posición del territorio. Esto es respaldado con el uso de encuestas, entrevistas y visitas de campo. En este sentido Sánchez (2014) sostiene la importancia de estudiar y explicar la planificación estratégica de planes desarrollados en los destinos. Para ello, se propone el diagnóstico, donde se analiza la oferta y la demanda turística del objeto de estudio, y se consideran herramientas que tienen como objetivo conocer la situación actual del destino.

Como expresa Hahm et al. (2018) la comercialización del producto turístico no es una actividad tan contemporánea. Sin embargo, la utilización frecuente de este término va evolucionando y desarrollándose mediante la aplicación de técnicas rigurosas como el estudio de la demanda, que a veces permite conocer las principales vías de comercialización para cada mercado. Por su parte Meng y Han (2018) consideran que la comercialización del producto turístico consiste en gestionar la idea y el servicio, y preparar a la empresa para hacer llegar, a los turistas, lo que ellos esperan con expectativas. Es decir, fortalecer los vínculos entre la oferta y la demanda.

Por otro lado, existe una serie de actividades que no se deben improvisar teniendo como meta la satisfacción. Para conseguir la efectividad en los procesos, es necesario que se consideren los canales de distribución como ejes importantes. Unido a ello se debe seguir el perfil y las características de lo que se quiere vender; así como definir las estrategias que permitan escoger las agencias y otras organizaciones de acuerdo con las necesidades del turista y la filosofía de la empresa. El enfoque de Jingyi y ChungShing (2018) resalta el diseño de productos innovadores que satisfagan diferentes clientes y se adapten a las tendencias actuales. Es necesario puntualizar que la dependencia de mercados específicos es una limitante que obliga a contar con una oferta diversa y dirigida a diferentes targets. De lo planteado anteriormente se deriva que todos estos aspectos son la base para una adecuada evaluación de las potencialidades. Para Hernández et al. (2020), los gobiernos y empresas tienen el reto de estudiar el futuro de los destinos por la complejidad del contexto. Una eficiente evaluación podrá visualizar de forma clara los lineamientos para su desarrollo.

La situación a nivel local resalta la importancia de este estudio, que tuvo como objetivo: evaluar las potencialidades turísticas de la parroquia Cojimíes, cantón Pedernales, Ecuador. La investigación se llevó a cabo sobre una base teórica formada 
por la literatura documental y especializada sobre el tema que se aborda. La información recabada sirvió para identificar los problemas y solucionarlas mediante estrategias basadas en las realidades locales. De ahí que la presente propuesta pretende ser una guía para el desarrollo turístico en la parroquia Cojimíes. Mediante la evaluación de las potencialidades se plantearon estrategias y acciones que guíen el fomento, la gestión y la promoción del turismo en la parroquia. Los lineamientos y la estructura de este estudio integran a todos los componentes del sistema turístico, donde los gestores y actores tendrán las herramientas para llevar a cabo acciones que permitan el fortalecimiento del turismo.

Cabe resaltar que esta investigación forma parte de los resultados de la tesis Plan de marketing turístico para la parroquia Cojimíes vinculada a un proyecto institucional de $1+D+i$ de la Escuela Superior Politécnica Agropecuaria de Manabí Manuel Félix López.

\section{MATERIALES Y MÉTODOS}

La investigación se desarrolló en la parroquia Cojimíes del cantón Pedernales, provincia Manabí, Ecuador. Tuvo un enfoque mixto (cualitativo y cuantitativo) y carácter descriptivo. En un primer momento realizó una revisión bibliográfica de documentos oficiales y de publicaciones especializadas. Posteriormente, se complementó la información con trabajo de campo y técnicas de observación directa. Para establecer el proceso metodológico, se planteó un análisis comparativo de diferentes estudios, donde se seleccionaron los que más se adaptaban al territorio y a sus realidades locales. Es por ello que el trabajo se sustentó en la propuesta del Ministerio del Ambiente de Ecuador (2014): Evaluación de efectividad de manejo del patrimonio de áreas naturales. Guía metodológica.

La figura1 muestra la localización del área de estudio.

Figura 1. Localización Cojimíes

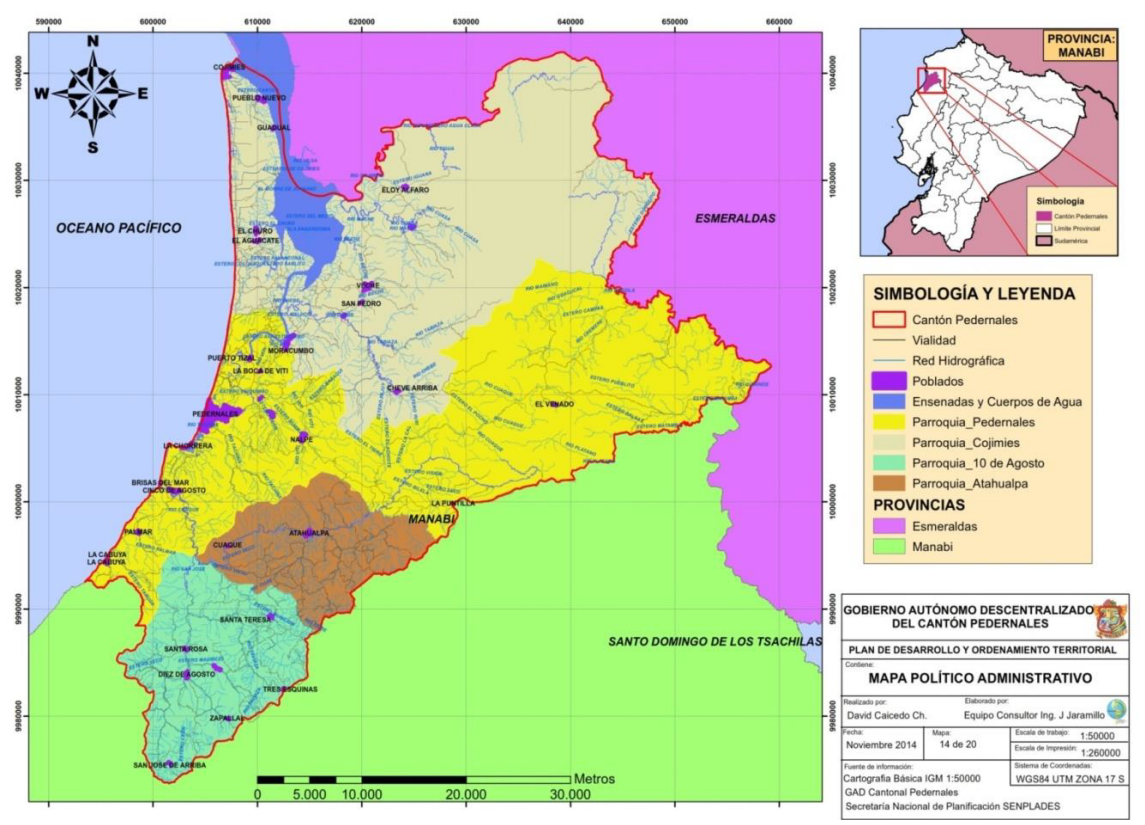

Fuente: Gobierno Autónomo Descentralizado Parroquial de Cojimíes (2015). 
La primera fase de esta investigación consistió en elaborar el diagnóstico del territorio. Con el fin de conocer la situación turística actual se realizó un levantamiento de información bibliográfica. Para ello se analizaron fuentes primarias y secundarias, como los planes de desarrollo y ordenamiento territorial de Pedernales y Cojimíes, páginas web oficiales e investigaciones realizadas en el área de estudio. Posteriormente se caracterizaron los servicios básicos, la infraestructura, los indicadores socioeconómicos e instalaciones turísticas mediante observación directa y visitas de campo. Además, se elaboró un análisis de la gobernanza y gestión del turismo local; para ello se realizaron nueve entrevistas a los actores y gestores del territorio, donde se identificaron las potencialidades, necesidades y desafíos para el desarrollo de la parroquia, y se elaboró una matriz de involucrados.

\section{Evaluación de las potencialidades turísticas del territorio}

Para el estudio de la competencia se eligieron dos destinos competidores con características similares, como son las playas de Pedernales y Mompiche. Para ello, se usó la matriz de perfil competitivo (David, 2003), donde se revisaron de manera individual los principales aspectos del sector turístico y se realizó la ponderación, dándole valor y puntaje a cada uno de los sitios elegidos. Luego, se realizó un análisis cuantitativo y cualitativo, destacando al de mayor puntaje como principal competidor. Esta herramienta permite identificar a los competidores más cercanos. Para ello se eligieron indicadores claves y su valor hasta completar 1 punto. La clasificación y valoración se expresó así: 1 = debilidad principal, 2 = debilidad menor, 3 = fortaleza menor, 4 = fortaleza principal. A continuación, se comparó y multiplicó el valor de los indicadores con la clasificación del lugar y se asignaron las ponderaciones.

Esta fase finalizó con un análisis turístico estratégico mediante la matriz FODA, lo que posibilitó identificar las fortalezas, oportunidades, debilidades y amenazas del territorio. La evaluación de estos factores internos y externos permitió identificar las estrategias apropiadas para el desarrollo del turismo en Cojimíes.

\section{RESULTADOS}

\section{Caracterización socioambiental y turística}

De acuerdo con el Gobierno Autónomo Descentralizado Parroquial de Cojimíes (2015), la parroquia pertenece al cantón Pedernales, región noroeste de la provincia Manabí. Ubicada al norte del territorio cantonal, tiene una altitud entre 2 y 71 m. s. n. m. y su extensión territorial es de $737.43 \mathrm{~km}^{2}$. Tiene una población de 13708 habitantes y cuenta con una densidad poblacional de $18.59 \mathrm{hab} / \mathrm{km}^{2}$ (Instituto Nacional de Estadísticas y Censos, 2010). El territorio está constituido principalmente por la Reserva Ecológica Mache-Chindul y por la punta Cojimíes. Además, resalta la 
presencia del estuario del río Cojimíes, sus recursos marino-costeros y el bosque de manglar. Posee un clima tropical semiárido, con una época seca, que comprende los meses de junio a noviembre, y otra lluviosa, entre diciembre y mayo. La temperatura tiene altas variaciones durante el año, que fluctúan entre un valor mínimo promedio de $20^{\circ} \mathrm{C}$ hasta un máximo aproximado de $33.7^{\circ} \mathrm{C}$.

En cuanto a la producción y la economía, Cojimíes posee un territorio extenso con áreas costeras y zonas rurales productivas utilizadas para la agricultura y la actividad pecuaria. El sistema económico en la región costera incluye la industria camaronera, la pesca artesanal, el turismo y el comercio (Gobierno Autónomo Descentralizado Parroquial de Cojimíes, 2015). A su vez, las autoridades manifiestan que el turismo en el territorio es el tercer componente de ingresos económicos y que contribuye con un $16.95 \%$ al Producto Interno Bruto del cantón, debido a los recursos naturales y culturales que posee. Actualmente, el sector turístico está en proceso de crecimiento y diversificación, pues se observa que nuevos emprendimientos de servicios están desarrollándose a la par con el aumento de la demanda existente.

\section{Análisis del sector turístico de acuerdo con la percepción de los actores y gestores locales}

Las nueve entrevistas aplicadas a los principales gestores y actores del turismo en la parroquia Cojimíes permitieron conocer su percepción sobre ese sector (tabla 1).

Tabla 1. Preguntas estratégicas de la entrevista

\begin{tabular}{ll}
\hline \multicolumn{1}{c}{ Objetivo: Analizar la gestión y gobernanza turística de la parroquia Cojimíes. } \\
\hline \multicolumn{1}{c}{ Dirigida a } & \multicolumn{1}{c}{ Temas claves } \\
\hline $\begin{array}{l}\text { GAD Pedernales } \\
\text {-Departamento de Planificación }\end{array}$ & $\begin{array}{l}\text {-Principales necesidades y problemáticas } \\
\text { del sector turístico en Cojimíes }\end{array}$ \\
-Dirección de Turismo & $\begin{array}{l}\text {-Implementación y servicios turísticos del } \\
\text { territorio }\end{array}$ \\
\hline $\begin{array}{l}\text { GAD Cojimíes } \\
\text {-Presidente de Junta Parroquial }\end{array}$ & $\begin{array}{l}\text {-Grado de satisfacción sobre la gestión } \\
\text {-Representante del área de desarrollo social } \\
\text {-Representante del área de turismo }\end{array}$ \\
\hline $\begin{array}{l}\text { Actores } \\
\text {-Asociación de Pescadores } \quad \text { Artesanales } \\
\text { (operación turismo Estuario) }\end{array}$ & $\begin{array}{l}\text {-Interés de participar en proyectos de } \\
\text {-Asociación de Hoteleros }\end{array}$ \\
$\begin{array}{l}\text {-Asociación de alimentos y bebidas } \\
\text {-Asociación de artesanos }\end{array}$ & -Programas y proyectos \\
\hline
\end{tabular}

Nota: GAD: Gobierno Autónomo Descentralizado Parroquial

Fuente: Elaboración propia. 
En este análisis se sistematizaron las preguntas que evaluaron al sector turístico y su gestión. Los gestores y actores consideraron que, después del sismo de 7.8 Mw ocurrido el 16 de abril de 2016, el turismo ha evolucionado de manera considerable. El mes de agosto y los feriados son las fechas más visitadas. La localización geográfica facilita la afluencia de turistas, principalmente de la región Sierra. Por su parte la planta turística de la parroquia es considerada adecuada. En el territorio se aprecia el crecimiento de inversiones en la estructura hotelera y en emprendimientos de alimentos y bebidas. Sin embargo, se evidencian problemáticas que limitan el desarrollo del turismo, entre ellos: la falta de alcantarillado sanitario y pluvial, el deficiente manejo de residuos sólidos y líquidos, la insuficiente señalética, la limitada accesibilidad e instalaciones turísticas, la baja calidad del servicio y la falta de capacitaciones.

\section{Matriz de involucrados}

En la matriz se sintetizaron los datos correspondientes a los principales grupos involucrados en el sector del turismo de la parroquia. Para su elaboración se tuvieron en cuenta: los problemas del territorio, el interés sobre proyectos de desarrollo y los conflictos que suceden entre los diferentes actores locales (tabla 2).

Tabla 2. Matriz de involucrados

\begin{tabular}{|c|c|c|c|}
\hline Grupos & Problemas & $\begin{array}{c}\text { Intereses sobre proyectos } \\
\text { de desarrollo }\end{array}$ & Conflictos \\
\hline $\begin{array}{c}\text { Departamento } \\
\text { de Turismo de } \\
\text { Pedernales }\end{array}$ & $\begin{array}{l}\text {-Débil presupuesto } \\
\text { direccionado al desarrollo } \\
\text {-Inestabilidad de los cargos } \\
\text { en la Dirección de Turismo } \\
\text {-Deficiente control en las } \\
\text { operaciones de actividades } \\
\text { turísticas }\end{array}$ & $\begin{array}{l}\text {-Implementación de } \\
\text { proyectos para mejorar la } \\
\text { accesibilidad e instalaciones } \\
\text { turísticas } \\
\text {-Mejorar la promoción } \\
\text { turística estratégica } \\
\text {-Programas de capacitación }\end{array}$ & $\begin{array}{l}\text {-Comunicación deficiente } \\
\text { entre el Gobierno } \\
\text { Autónomo Descentralizado } \\
\text { cantonal y el parroquial } \\
\text {-Priorización de objetivos } \\
\text { particulares y no objetivos } \\
\text { comunes }\end{array}$ \\
\hline $\begin{array}{l}\text { Junta Parroquial } \\
\text { de Cojimíes }\end{array}$ & $\begin{array}{l}\text {-Ubicación de personal no } \\
\text { calificado en turismo como } \\
\text { representante local } \\
\text {-Inexistencia de } \\
\text { planificaciones que } \\
\text { direccionen la actividad } \\
\text { turística en el territorio } \\
\text {-Deficientes ordenanzas } \\
\text { direccionadas a la actividad } \\
\text { turística } \\
\text {-Débil apoyo en cuanto a la } \\
\text { gestión, capacitación e } \\
\text { implementación de } \\
\text { facilidades para el turismo } \\
\text { local }\end{array}$ & $\begin{array}{l}\text {-Capacitaciones sobre } \\
\text { gestión turística } \\
\text {-Elaboración de un plan de } \\
\text { marketing } \\
\text {-Propuestas de normativas } \\
\text { locales para direccionar el } \\
\text { turismo } \\
\text {-Establecimiento de } \\
\text { acciones para desarrollar el } \\
\text { turismo local }\end{array}$ & $\begin{array}{l}\text {-Insuficiente comprensión } \\
\text { entre gestores y actores } \\
\text { locales } \\
\text {-Desorden en el uso del } \\
\text { territorio para las } \\
\text { actividades turísticas }\end{array}$ \\
\hline
\end{tabular}




\begin{tabular}{|c|c|c|c|}
\hline \multirow{5}{*}{$\begin{array}{l}\text { Asociaciones de } \\
\text { servicios } \\
\text { turísticos }\end{array}$} & $\begin{array}{l}\text {-Débil comunicación entre } \\
\text { asociaciones de servicios } \\
\text { turísticos }\end{array}$ & $\begin{array}{l}\text {-Fortalecimiento de las } \\
\text { relaciones entre el sector } \\
\text { público y privado }\end{array}$ & $\begin{array}{l}\text {-Limitada vinculación entre } \\
\text { los miembros con el sector } \\
\text { público }\end{array}$ \\
\hline & $\begin{array}{l}\text {-Deficiente capacitación en } \\
\text { cuestión de asociatividad }\end{array}$ & \multirow{2}{*}{$\begin{array}{l}\text {-Establecimiento de } \\
\text { programas para fortalecer } \\
\text { la asociatividad social }\end{array}$} & \multirow{4}{*}{$\begin{array}{l}\text {-Desintegración entre los } \\
\text { miembros de las } \\
\text { asociaciones }\end{array}$} \\
\hline & -Insuficiente incentivo & & \\
\hline & $\begin{array}{l}\text { económico por parte de los } \\
\text { Gobiernos cantonal y } \\
\text { parroquial }\end{array}$ & \multirow{2}{*}{$\begin{array}{l}\text {-Implementación de } \\
\text { estrategias para el } \\
\text { mejoramiento del servicio } \\
\text { turístico }\end{array}$} & \\
\hline & $\begin{array}{l}\text {-Inexistencia de una } \\
\text { planificación que dirija las } \\
\text { acciones para el } \\
\text { mejoramiento del servicio } \\
\text { turístico }\end{array}$ & & \\
\hline
\end{tabular}

Fuente: Elaboración propia.

De acuerdo con la tabla 2, en lo que respecta a la gestión y manejo del turismo en la parroquia de Cojimíes, se evidenció que el principal representante es la Dirección de Turismo de Pedernales, institución responsable de la gestión. Hay que destacar como problemas relevantes: el limitado presupuesto destinado al desarrollo, la inestabilidad de los cargos en la Dirección de Turismo y el deficiente control en las operaciones de actividades turísticas. Otro organismo importante a nivel local es la Junta Parroquial, encargada de forma directa del manejo del territorio, y donde existe una comisión para la gestión del turismo. Dentro de los problemas identificados están: presencia de personal no especializado, inexistencia de planificaciones que encaminen la actividad de forma eficiente; de hecho, no existen ordenanzas locales que organicen y fiscalicen la actividad. Finalmente, la relación entre los gestores y actores locales es deficiente por la falta de comunicación y coordinación.

\section{Recursos turísticos potenciales}

El balneario se encuentra en el estuario del río Cojimíes y es un hábitat de manglares poseedor de recursos turísticos, como la Isla del Amor, la playa Cojimíes y punta Palmar. Además, se realizan varios festivales gastronómicos y culturales. En la tabla 3 se presentan los principales recursos naturales y culturales, y sus características más importantes.

El estuario del río Cojimíes es un ecosistema de humedales (estuario-manglar) que tiene altos índices de potencialidades turísticas. Actualmente, se desarrollan actividades como la pesca deportiva, los paseos acuáticos y la observación de flora y fauna. Es el escenario donde acontecen las competencias de pesca deportiva del Festival Internacional de la Corvina y el Róbalo, (Argyrosomus regius y Centropomus undecimalis, respectivamente). Para la práctica del turismo, se toma como centro de operaciones la planta de la parroquia y playa Cojimíes. Este es el lugar propicio 
en el que los visitantes, además de bañarse o descansar a orillas del mar, pueden practicar actividades deportivas acuáticas, recreación y contemplación. Posee una estructura que ofrece servicios de alojamiento, gastronomía y artesanías.

Tabla 3. Recursos turísticos potenciales balneario Cojimíes

\begin{tabular}{|c|c|c|}
\hline \multicolumn{3}{|c|}{ Recursos naturales } \\
\hline $\begin{array}{l}\text { Nombre del } \\
\text { recurso }\end{array}$ & Descripción & Fotografías \\
\hline Isla del Amor & $\begin{array}{l}\text { Localizada frente a la playa Cojimíes, tiene } \\
\text { una extensión de } 45 \text { ha. Se encuentra } \\
\text { formada por bancos y sedimentos arenosos } \\
\text { de características estuarinas. Su vegetación } \\
\text { forma parte del ecosistema marino-costero } \\
\text { y se localiza a } 2 \mathrm{~km} \text { de la parte continental. } \\
\text { Actualmente, cuenta con instalaciones } \\
\text { turísticas (mirador, senderos y } \\
\text { sombreadores). }\end{array}$ & \\
\hline Playa Cojimíes & $\begin{array}{l}\text { Es un lugar con predominio del régimen } \\
\text { oceánico y tiene influencia de aguas } \\
\text { estuarinas en la denominada punta Cojimíes, } \\
\text { que es la entrada al estuario del mismo } \\
\text { nombre. La longitud es de } 4 \mathrm{~km} \text { y el color de } \\
\text { sus aguas es verde claro, con arena fina y } \\
\text { gris en la parte oceánica. El ancho de la } \\
\text { playa en la zona de uso público es de } 200 \mathrm{~m} \\
\text { en la parte oceánica. }\end{array}$ & \\
\hline $\begin{array}{l}\text { Estuario del río } \\
\text { Cojimíes }\end{array}$ & $\begin{array}{l}\text { Se ubica en el límite político entre las } \\
\text { provincias Esmeraldas y Manabí. Tiene una } \\
\text { longitud aproximada de } 25 \mathrm{~km} \text { y un área de } \\
180 \mathrm{~km}^{2} \text {. Inicia desde la parte superior del } \\
\text { río Cojimíes y la desembocadura en la zona } \\
\text { costera. Se observa la presencia de cinco } \\
\text { especies de mangles. Es parte del Refugio de } \\
\text { Vida Silvestre Muisne-Cojimíes del Sistema } \\
\text { Nacional de Áreas Protegidas del Ecuador. }\end{array}$ & \\
\hline \multicolumn{3}{|c|}{ Recursos culturales } \\
\hline $\begin{array}{c}\text { Festival } \\
\text { Internacional } \\
\text { de la Corvina y } \\
\text { el Róbalo }\end{array}$ & $\begin{array}{l}\text { Posee un alto nivel de asistencia, tanto de } \\
\text { turistas nacionales como extranjeros con la } \\
\text { intención de pescar la corvina y el róbalo } \\
\text { más grande. Se realiza en el estuario del río } \\
\text { Cojimíes. Durante el evento, se realizan } \\
\text { varias actividades como regatas a vela, } \\
\text { presentaciones artísticas, gastronomía } \\
\text { típica, fiestas y la elección de la reina del } \\
\text { festival. Es desarrollado de manera anual en } \\
\text { el mes de agosto. }\end{array}$ & \\
\hline
\end{tabular}




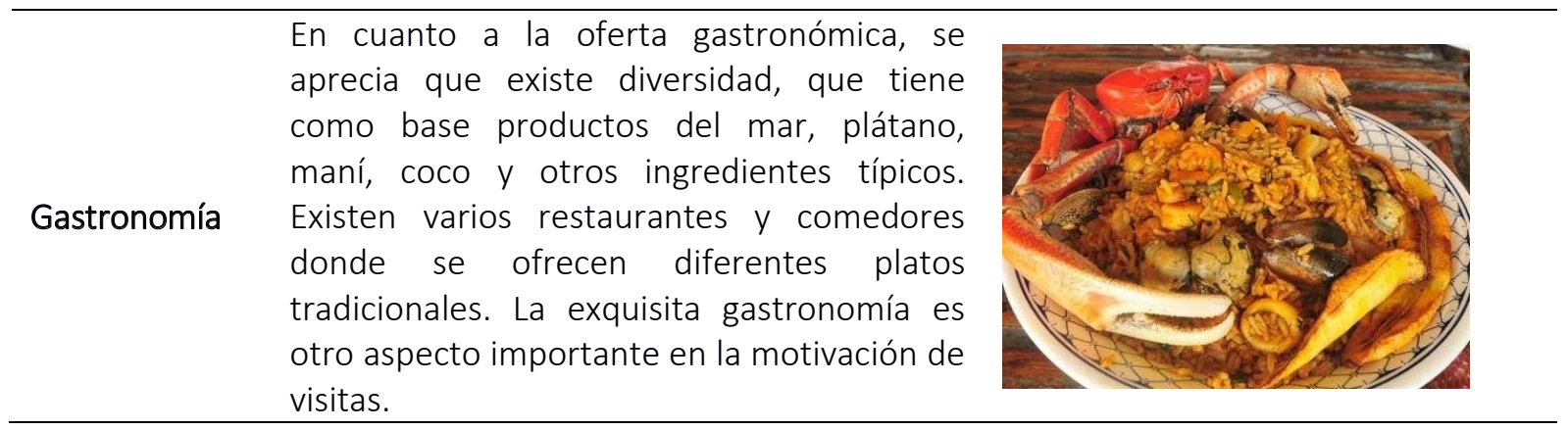

Fuente: Elaboración propia.

\section{Análisis del territorio mediante matriz de perfil competitivo}

Para esta evaluación, se eligieron los principales competidores de la parroquia Cojimíes, como son: las playas de Pedernales y Mompiche. Mediante un análisis bibliográfico y de salidas de campo, se observaron los siguientes indicadores socioecológicos y económicos: servicios básicos, recursos turísticos, conservación ambiental, planta turística, oferta de productos, promoción, reconocimiento en el mercado, vialidad, localización y precios.

A continuación, se presenta la matriz de perfil competitivo que muestra las características turísticas y su ponderación (tabla 4).

Tabla 4. Matriz de perfil competitivo

\begin{tabular}{|c|c|c|c|c|c|c|c|}
\hline \multirow{2}{*}{$\begin{array}{l}\text { Indicadores } \\
\text { de éxito }\end{array}$} & \multirow{2}{*}{ Valor } & \multicolumn{2}{|c|}{ Cojimíes } & \multicolumn{2}{|c|}{ Playa Pedernales } & \multicolumn{2}{|c|}{ Playa Mompiche } \\
\hline & & Clasificación & Puntaje & Clasificación & Puntaje & Clasificación & Puntaje \\
\hline Servicios básicos & 0.07 & 1 & 0.07 & 2 & 0.14 & 1 & 0.07 \\
\hline $\begin{array}{l}\text { Recursos } \\
\text { turísticos }\end{array}$ & 0.10 & 4 & 0.40 & 3 & 0.30 & 4 & 0.40 \\
\hline $\begin{array}{l}\text { Conservación de } \\
\text { recursos }\end{array}$ & 0.10 & 2 & 0.20 & 2 & 0.20 & 2 & 0.20 \\
\hline Planta turística & 0.20 & 3 & 0.60 & 4 & 0.80 & 3 & 0.60 \\
\hline $\begin{array}{l}\text { Oferta de } \\
\text { productos }\end{array}$ & 0.20 & 3 & 0.60 & 2 & 0.40 & 3 & 0.60 \\
\hline $\begin{array}{l}\text { Promoción y } \\
\text { reconocimiento } \\
\text { en el mercado }\end{array}$ & 0.15 & 1 & 0.15 & 3 & 0.45 & 3 & 0.45 \\
\hline $\begin{array}{l}\text { Vialidad y } \\
\text { localización }\end{array}$ & 0.10 & 4 & 0.40 & 4 & 0.40 & 3 & 0.30 \\
\hline Precios & 0.08 & 3 & 0.24 & 3 & 0.24 & 3 & 0.24 \\
\hline TOTAL & 1 & & 2.66 & & 2.93 & & 2.86 \\
\hline
\end{tabular}

Fuente: Elaboración propia.

En cuanto a los resultados de la ponderación, se pudo observar que la playa Pedernales es el principal competidor, con un total de 2.93 puntos. Los indicadores con mayor representatividad fueron la promoción y la planta turística. En tanto, la playa Mompiche tuvo como resultado 2.86 puntos y su factor más destacado fue la promoción. Es 
necesario aclarar que la playa Cojimíes se asemeja con la playa Mompiche en indicadores como recursos turísticos, planta turística y oferta de productos. Por su parte la playa Pedernales se diferencia de las anteriores por la limitada oferta de productos. Se debe recalcar que los tres sitios tienen como debilidad la deficiencia en servicios básicos y la similitud en el precio de los servicios ofrecidos. Un punto favorable para el desarrollo del turismo en Cojimíes es la vialidad y localización, lo que facilita la conectividad con otros destinos que contribuyen a la afluencia de turistas de diferentes provincias del país.

\section{Análisis turístico estratégico}

El diagnóstico integral del territorio se realizó mediante la revisión bibliográfica, las visitas de campo y las entrevistas a los gestores y actores y se analizaron los elementos que forman parte del sistema turístico de la parroquia. En la tabla 5 se resumen las fortalezas, oportunidades, debilidades y amenazas que fueron identificadas mediante la matriz FODA, según los resultados de la ponderación.

Tabla 5. Análisis FODA de Cojimíes

\section{Fortalezas}

1. Diversidad de recursos naturales y culturales, ecosistemas marino-costeros y bosque húmedo tropical

2. Conservación de la diversidad biológica marino-costero en dos áreas protegidas: Mache-Chindul y Refugio de Vida Silvestre Muisne-Cojimíes

3. Posicionamiento como destino turístico regional por sus playas y gastronomía

4. Localización estratégica por la conectividad y distancia con otros cantones posicionados como sitios turísticos

5. Interés de los actores sociales en mejorar la operación del turismo local

6. Microempresarios locales motivados en fomentar el turismo y ofrecer servicio de calidad

7. Buen estado de conservación de sus principales vías de acceso

8. Festivales y eventos gastronómicos reconocidos a nivel regional y nacional

\section{Debilidades}

1. Insuficiencia de servicios básicos (saneamiento)

2. Extracción de madera (deforestación), cacería, pesca ilegal y expansión de la frontera agropecuaria sin respetar el ordenamiento territorial

3. Mínima ejecución de proyectos turísticos direccionados a la accesibilidad y ordenamiento territorial

4. Deficiente gobernanza y coordinación entre actores turísticos locales

5. Limitada planificación y recursos económicos para el desarrollo de la actividad turística

6. Escasas ordenanzas municipales, en temas de turismo y planificación territorial, dirigidas a la conservación y manejo sostenible

7. Gestores turísticos no capacitados

8. Inexistencia de un plan de marketing turístico que promocione de manera estratégica a la parroquia Cojimíes como destino turístico

9. Limitada seguridad y manejo turístico en actividades de recreación en la parroquia. 


\section{Oportunidades}

1. Proyectos del Plan Reconstruyo Ecuador, por el terremoto del 16 de abril 2016

2. Turismo político de Estado, integrando los destinos afectados por el movimiento telúrico

3. Cercanía a los centros de demanda turística y punto de unión con diferentes destinos de interés

4. Presencia de instituciones educativas (universidades) que desarrollan investigaciones y proyectos de conservación

5. Incentivos económicos para nuevos proyectos de emprendimientos locales de parte de varias ONG

6. Condiciones para el desarrollo del turismo de naturaleza, rural y comunitario enfocados en planificaciones nacionales

7. Tendencia internacional creciente de los segmentos de naturaleza, aventura y ecoturismo

\section{Amenazas}

1. Zonas sísmicas y de fenómenos atmosféricos.

2. Aparición de enfermedades infectocontagiosas (dermatitis, dengue, hepatitis, infección intestinal)

3. Inseguridad, delincuencia

4. Inestabilidad política local

5. Crisis económica a nivel nacional

Fuente: Elaboración propia.

Como se evidencia en la tabla 5, a pesar de contar con el interés de los gestores y actores sociales para mejorar la operación del turismo local y el posicionamiento como destino turístico regional, por sus playas y gastronomía, no evidencia resultados satisfactorios. Se pueden observar debilidades que limitan su desarrollo como la inexistencia de un plan de marketing turístico que promocione de manera estratégica a la parroquia, la mínima ejecución de proyectos dirigidos a mejorar la accesibilidad y al ordenamiento territorial, además de la deficiente coordinación entre actores y gestores turísticos locales.

\section{Estrategias para el desarrollo turístico de Cojimíes}

Considerando los resultados de la matriz FODA, a continuación, se presentan los proyectos, estrategias y acciones propuestos. Mediante la planificación, se plantea mejorar la productividad turística de la parroquia, dando soluciones a las principales necesidades basadas en la realidad local y el aprovechamiento de las oportunidades que hay en el territorio:

- Mejorar la gobernanza y coordinación entre actores turísticos, fortaleciendo los procesos de gestión y vinculación.

- Mejorar los servicios básicos e infraestructura mediante el aprovechamiento y reactivación de los proyectos del Plan Reconstruyo Ecuador.

- Elaborar proyectos turísticos direccionados a la accesibilidad y el ordenamiento territorial.

- Mejorar la promoción turística de Cojimíes a través de un plan de marketing que siga la tendencia internacional creciente de los 
segmentos de naturaleza, aventura y ecoturismo.

- Conservar los recursos turísticos mediante proyectos de sostenibilidad, aprovechando la presencia de instituciones educativas (universidades).
Con el objetivo de plantear y organizar de forma concreta las estrategias para el desarrollo del turismo en Cojimíes, se presenta en la tabla 6 una serie de proyectos adaptados a la realidad local.

Tabla 6. Proyectos y acciones para el desarrollo turístico de Cojimíes

\begin{tabular}{|c|c|c|c|}
\hline Problemas & Objetivos generales & Proyectos & Acciones \\
\hline \multirow[b]{2}{*}{$\begin{array}{l}\text { Falta de personal } \\
\text { cualificado en turismo }\end{array}$} & \multirow{2}{*}{$\begin{array}{l}\text { Consolidar la } \\
\text { sostenibilidad e impulsar } \\
\text { el desarrollo para el } \\
\text { fortalecimiento del } \\
\text { turismo en las } \\
\text { comunidades }\end{array}$} & \multirow{2}{*}{$\begin{array}{l}\text { Involucramiento } \\
\text { entre los } \\
\text { principales } \\
\text { actores y } \\
\text { gestores locales }\end{array}$} & $\begin{array}{l}\text { Desarrollar talleres } \\
\text { participativos y la } \\
\text { vinculación comunitaria }\end{array}$ \\
\hline & & & $\begin{array}{l}\text { Identificar proyectos } \\
\text { innovadores que integren la } \\
\text { producción y las } \\
\text { potencialidades locales }\end{array}$ \\
\hline \multirow{5}{*}{ Mal manejo territorial } & \multirow{5}{*}{$\begin{array}{l}\text { Fomentar estrategias } \\
\text { sostenibles que } \\
\text { incorporen la } \\
\text { conservación y el uso } \\
\text { racional de los recursos } \\
\text { naturales de los } \\
\text { humedales }\end{array}$} & \multirow{2}{*}{$\begin{array}{l}\text { Educación } \\
\text { ambiental }\end{array}$} & $\begin{array}{l}\text { Capacitar a la población } \\
\text { local sobre gestión } \\
\text { sostenible }\end{array}$ \\
\hline & & & $\begin{array}{l}\text { Realizar campañas de } \\
\text { sensibilización ambiental } \\
\text { con las unidades educativas } \\
\text { de la región }\end{array}$ \\
\hline & & \multirow{3}{*}{$\begin{array}{l}\text { Gestión de } \\
\text { recursos } \\
\text { naturales }\end{array}$} & $\begin{array}{l}\text { Gestionar y controlar los } \\
\text { desechos }\end{array}$ \\
\hline & & & $\begin{array}{l}\text { Fortalecer las políticas de } \\
\text { ordenamiento territorial }\end{array}$ \\
\hline & & & $\begin{array}{l}\text { Mantener los recursos } \\
\text { naturales y la infraestructura } \\
\text { turística ambiental }\end{array}$ \\
\hline \multirow{3}{*}{$\begin{array}{l}\text { Infraestructura } \\
\text { turística en proceso } \\
\text { de deterioro y } \\
\text { limitada innovación } \\
\text { de productos }\end{array}$} & \multirow{3}{*}{$\begin{array}{l}\text { Impulsar la economía de } \\
\text { las comunidades } \\
\text { asentadas en los } \\
\text { alrededores de los } \\
\text { humedales, a través del } \\
\text { desarrollo y difusión de } \\
\text { productos turísticos que } \\
\text { permitan el } \\
\text { aprovechamiento de los } \\
\text { recursos }\end{array}$} & \multirow{3}{*}{$\begin{array}{l}\text { Fortalecimiento } \\
\text { turístico de las } \\
\text { áreas }\end{array}$} & $\begin{array}{l}\text { Crear productos } \\
\text { innovadores integrados que } \\
\text { aprovechen los recursos } \\
\text { naturales y culturales }\end{array}$ \\
\hline & & & $\begin{array}{l}\text { Establecer campañas de } \\
\text { promoción turística digital }\end{array}$ \\
\hline & & & $\begin{array}{l}\text { Gestionar vínculos con } \\
\text { entidades públicas y } \\
\text { privadas }\end{array}$ \\
\hline
\end{tabular}

Fuente: Elaboración propia.

Las acciones observadas en la tabla 6 surgieron del diagnóstico, el cual evidenció las potencialidades turísticas de la parroquia Cojimíes. Además de los servicios de alimentación y hospedaje existentes, es necesario diversificar su oferta de productos. Se observó que el territorio no se limita a recursos de "sol y playa», sino que existen 
sitios con biodiversidad y actividades socioproductivas rurales que pueden ser desarrolladas con un enfoque turístico sostenible.

\section{DISCUSIÓN}

Al hacer un análisis de la situación actual y de las potencialidades turísticas de la parroquia Cojimíes, es necesario considerar antecedentes como el sismo de magnitud 7.8 Mw ocurrido el 16 de abril del 2016. Este afectó de forma directa la planta e infraestructura turística de la región con efectos gravísimos para la población y empresarios locales. Actualmente, la actividad del turismo ha evolucionado de manera considerable. Los meses de agosto, los días feriados y los fines de semana son las fechas más visitadas. La localización geográfica permite la afluencia de turistas, principalmente de la región Sierra. En lo que respecta a la planta turística, en tiempos actuales se considera adecuada, ya que se evidencia el crecimiento de la estructura hotelera y de los servicios de alimentos y bebidas; impulsados por la oferta de «sol y playa» y gastronomía. En el territorio se pueden observar varios recursos turísticos, como áreas protegidas con ecosistemas de bosque húmedo tropical, reservas ecológicas marino-costeras y festivales gastronómicos con altos niveles de atractivo.

Es importante recalcar que la gestión y manejo del turismo en la parroquia de Cojimíes tiene como representante principal a la Dirección de Turismo de Pedernales, la cual es responsable por la gestión en todo el territorio, tanto en sus parroquias rurales como en las urbanas. Los problemas que más se destacan son el limitado presupuesto, la inestabilidad de los cargos en la Dirección de Turismo y el deficiente control en las operaciones de actividades turísticas. Otro organismo importante a nivel local es la Junta Parroquial, siendo la encargada de forma directa del manejo del territorio. Existiendo una comisión direccionada a la gestión del turismo, se observan como problemas principales la contratación de funcionarios no especializados en turismo, además de la inexistencia de planificaciones sostenibles. Tampoco hay ordenanzas locales que organicen y fiscalicen la actividad. Finalmente, la relación entre los gestores y actores locales es deficiente por la falta de comunicación y coordinación.

De acuerdo con las exigencias del mercado internacionalylasnecesidades dela población local, es evidente la falta de alcantarillado sanitario y pluvial. En época de Iluvia, las calles principales se inundan, trayendo consigo insalubridad e incomodidad. El deficiente manejo de residuos sólidos y líquidos se torna otro inconveniente. Según el criterio de los gestores locales, existen deficiencias con la señalética, la accesibilidad y las instalaciones turísticas en cada uno de los recursos, además de una deficiente calidad del servicio y falta de capacitaciones continuas en todo el territorio. En resumen, la parroquia Cojimíes, a pesar de contar con el interés de los actores sociales en mejorar la operación del turismo local, muestra debilidades que limitan su desarrollo. Entre ellos, se evidencian la mínima ejecución de proyectos dirigidos a la accesibilidad y al ordenamiento territorial. 


\section{CONCLUSIONES}

Se evidenció que la parroquia posee atractivos turísticos como la Reserva Ecológica Mache-Chindul y punta Cojimíes, con el estuario del río del mismo nombre, donde existen recursos marino-costeros como el bosque de manglar, ecosistemas estuarinos y playas. Según la percepción de los gestores y actores locales, la actividad turística tuvo afectaciones severas por el sismo del 16 de abril de 2016. Actualmente se percibe una recuperación de su infraestructura hotelera, gastronómica y vial. La mayor afluencia de turista coincide con las vacaciones de la región Sierra (julio y agosto), el feriado de Carnaval y la Semana Santa. Su localización geográfica favorece la afluencia de turistas, principalmente de la región Sierra y Amazonía. En lo que respecta a la planta turística de la parroquia, se considera adecuada, ya que se ven grandes inversiones, especialmente, en la estructura hotelera y en la accesibilidad vial.

El análisis de la matriz de perfil competitivo determinó que la playa Pedernales es el principal competidor de Cojimíes, con un total de 2.93 puntos. La promoción y la planta turística fueron los indicadores con mayor representatividad en los tres destinos analizados.

Como resultado de la evaluación del territorio y mediante la utilización de las herramientas descritas, se presentan siete estrategias que buscan mejorar la productividad turística de la parroquia, mediante la planificación. Las soluciones a las principales necesidades se basan en la realidad local y el aprovechamiento de las oportunidades locales. Entre las acciones propuestas se destacan mejorar la gobernanza y coordinación entre los actores turísticos, fortaleciendo los procesos de gestión y vinculación. De igual modo se requiere adecuar los servicios básicos e infraestructura mediante el aprovechamiento y reactivación de los proyectos del Plan Reconstruyo Ecuador y elaborar proyectos turísticos encaminados a mejorar la accesibilidad y ordenamiento territorial.

\section{REFERENCIAS BIBLIOGRÁFICAS}

Ayoví, L. (2018). Diseño de un plan de marketing turístico para el cantón Puerto Quito, provincia de Pichincha periodo 2017. [Tesis de pregrado, Escuela Superior Politécnica de Chimborazo]. Repositorio Institucional ESPOCH. https://bit.ly/305xD4g

Buciega, A. y Esparcia, J. (2018). Desarrollo, territorio y capital social. Un análisis a partir de dinámicas relacionales en el desarrollo rural. Redes. Revista hispana para el análisis de redes sociales, 24(1), 81-113. https://doi.org/10.5565/rev/redes.350

Cardoso, C., Castillo, M. y Hernández, C. (2014). Sosteniendo al turismo o turismo sostenible (TS). Reflexiones teóricas. Estudios y perspectivas en turismo, 23(2), 376-395. https://bit.ly/3uwY19r 
Carreño, A., García, N. y Doumet, N. (2017). Diagnóstico turístico estratégico. Caso de estudio del cantón Bolívar, Manabí, Ecuador. Editorial Humus.

Cruz, L. D. y González, A. (2020). Desarrollo turístico y sostenibilidad en la comunidad de Caibarién (Cuba). Revista Internacional de Turismo, Empresa y Territorio, 4(2), 103-127 https://doi.org/10.21071/riturem.v4i2.12876

David, F. (2003). Conceptos de Administración Estratégica (9. ed.). Pearson Educación.

Gobierno Autónomo Descentralizado Parroquial de Cojimíes. (2015). Plan de desarrollo y ordenamiento territorial de la parroquia Cojimíes (2015-2019). https://bit.ly/3h8S7rl

Gómez, L. y Tacuba, A. (2017). La política de desarrollo rural en México. ¿Existe correspondencia entre lo formal y lo real? Economía Unam, 14(42), 93-117. https://bit.ly/3ezhocs

Hahm, J., Tasci, A. y Terry, D. (2018). Investigating the interplay among the Olympic Games image, destination image, and country image for four previous hosts. Journal of Travel \& Tourism Marketing, 35(6) 755-771. https://doi.org/10.1080/10548408.2017.1421116

He, X., Hu, D., Swanson, S. R., Su, L. y Chen, X. (2018). Destination perceptions, relationship quality, and tourist environmentally responsible behavior. Tourism Management Perspectives, 28, 93-104. https://doi.org/10.1080/10548408.2017.1421116

Hernández, Y., Sánchez, Y., Saldiña, B. y Rives, K. A. (2020). Características de la demanda potencial del destino Cuba en la nueva normalidad postcoronavirus. Revista Internacional de Turismo, Empresa y Territorio, 4(2), 158-177. https://doi.org/10.21071/riturem. $\underline{\mathrm{v} 4 \mathrm{i} 2.13050}$

Instituto Nacional de Estadísticas y Censos. (2010). Información censal cantonal. https://bit.ly/2RJtBT2

Jingyi, L. y Chung-Shing, C. (2018). Local cultural vicissitudes in regional tourism development: A case of Zhuhai. Tourism Management Perspectives, 25, 80-92. https://doi.org/10.1016/i. tmp.2017.11.016

Lee, T. H., Jan, F-H., Tseng, C. H. y Lin, Y. F. (2018). Segmentation by recreation experience in islandbased tourism: A case study of Taiwan's Liuqiu Island. Journal of Sustainable Tourism, 26(3), 362-378. https://doi.org/10.1080/09669582.2017.1354865

Martín, I. y Martín, F. (2017). Interpretación del patrimonio y gestión sostenible del turismo en espacios rurales. Los casos de Montejo de la Sierra y Patones. Boletín de la Asociación de Geógrafos Españoles, (72), 169-194. https://doi.org/10.21138/bage.2336 
Meng, B. y Han, H. (2018). Investigating individuals' decision formation in working-holiday tourism: the role of sensation-seeking and gender. Journal of Travel \& Tourism Marketing, 35(8), 973-987. https://doi.org/10.1080/10548408.2017.1422455

Mera, A. V. y Solórzano, D. P. (2017). Plan de marketing turístico territorial que fomente el desarrollo sostenible del cantón Chone. [Tesis de pregrado, Escuela Superior Politécnica Agropecuaria de Manabí Manuel Félix López]. Repositorio Institucional ESPAM-MFL. https://bit.ly/3h9bkZz

Ministerio de Turismo de Ecuador. (2014). Proyecto Ecuador potencia turística. https://bit. $\underline{\text { ly/2SBHi6X }}$

Ministerio del Ambiente de Ecuador. (2014). Evaluación de efectividad de manejo del patrimonio de áreas naturales del Estado. Guía metodológica. https://bit.ly/3uwDBgX

Organización de las Naciones Unidas. (s.f.). Desarrollo sostenible. https://bit.ly/3y1nkT8

Reyes, M. V., Manjarrez, N. N. y Ortega, A. F. (2014). La gestión del turismo comunitario en el marco de la economía popular y solidaria en Ecuador. Revista Turydes: Turismo y Desarrollo, 7(17). https://bit.ly/3f3yCh8

Roldán, J. M., Caridad, J. M. y Pérez, J. C. (2017). El perfil del turista cinegético: un estudio de caso para Córdoba (España). International Journal of Scientific Management and Tourism, 3(4), 187-203. https://bit.ly/3bjejuz

Sánchez, M. (2014). Plan de Marketing de destinos turísticos Zamora. [Tesis de grado, Universidad de Valladolid]. Repositorio Institucional UVA. http://uvadoc.uva.es/handle/10324/5515

Shen, L., Xiong, B. y Hu, J. (2017). Research status, hotspots and trends for information behavior in China using bibliometric and co-word analysis. Journal of Documentation, 73(4), 618633. https://doi.org/10.1108/JD-10-2016-0125

Solórzano, S. K. (2019). Plan de marketing para el desarrollo turístico de la parroquia Cojimíes provincia de Manabí. [Tesis de pregrado, Escuela Superior Politécnica Agropecuaria de Manabí Manuel Félix López]. Repositorio Institucional ESPAM-MFL. https://bit.ly/3uBhOo9

Zengxian, L. y Jigang, B. (2018). Targeted poverty alleviation in China: segmenting small tourism entrepreneurs and effectively supporting them. Journal of Sustainable Tourism, 26(11), 1984-2001. https://doi.org/10.1080/09669582.2018.1526296 